\title{
Multicriteria Scenario Analysis on Electricity Production
}

\author{
Maria João Santos \\ Department of Production and Systems \\ University of Minho \\ Guimarães, Portugal \\ mjoaosantos@dps.uminho.pt
}

\author{
Paula Ferreira \\ Department of Production and Systems \\ University of Minho \\ Guimarães, Portugal \\ paulaf@dps.uminho.pt
}

\author{
Madalena Araújo \\ Department of Production and Systems \\ University of Minho \\ Guimarães, Portugal \\ mmaraujo@dps.uminho.pt
}

\begin{abstract}
Energy planning is a complex process involving multiple and conflicting objectives with many agents able to influence decisions. This complexity is frequently addressed with the use of multicriteria tools, relying on a set of criteria and different methods to aggregate all the information in a final ranking of the available alternatives. This paper describes the application of a multicriteria decision tool for the analysis of Portuguese electricity scenarios. A set of criteria is proposed aiming to include social, economic, environmental and technical aspects. Criteria weighting was directly addressed considering 5 approaches: equitable weights, financial, technological, social and environmental perspectives. Results indicate that close to $100 \%$ RES scenario is the best option under a social perspective, base scenario represents the best option on a technical approach and scenarios relying on natural gas and wind power units are the best options for the electricity system under equitable weights, economic and environmental approaches.
\end{abstract}

Index Terms-- electricity scenarios, multicriteria, $100 \%$ renewable

\section{INTRODUCTION}

The search for reliable and less polluting technologies for the electricity generation, without compromising the national economic growth, has been on the top of the decision-makers' concerns [1]. In this context, renewable energy sources (RES) play an important role, becoming a suitable investment for a low carbon future. Portugal presents a privileged access to a vast set of RES, such as hydro, wind, biomass and sun, and the achievement of a $100 \%$ renewable electricity system may be a way to indorse a sustainable form to produce electricity, totally independent from fossil fuel suppliers. However, some limitations derive from a highly renewable electricity system namely the need for mature technologies, grid integration and backup systems.

Least-cost evaluation can no longer be the only option to consider in the electricity power planning, as environmental, social and technical aspects must also be undertaken. Nevertheless, each criterion has its own target, usually resulting in conflicting objectives between different criteria. One efficient set of tools to deal with these problems is multi- criteria decisions analysis (MCDA) [2]. However, MCDA usually implies collecting a large set of data from literature and from participative processes which can be highly resource consuming.

The aim of this work is to demonstrate how MCDA can help policy makers on going beyond the evident cost and environmental criteria relying on a simple MCDA tool based on tradeoff analysis. The tool is used to compare 5 different scenarios for the Portuguese electricity system to meet demand until 2030.

\section{METHODOLOGY}

The work started with the proposal of 5 scenarios, which were constructed using an adapted version of the long term optimization model developed on the SEPP project (Sustainable Electricity Power Planning) and described in [3]. Table I presents the scenarios. Their designation reflects the main type of electricity generation technologies which characterizes them.

TABLE I. SCENARIOS DESCRIPTION

\begin{tabular}{|c|c|}
\hline $\begin{array}{c}\text { Scenario } \\
\text { number }\end{array}$ & Scenario designation \\
\hline 1 & Base \\
\hline 2 & Coal + Biomass \\
\hline 3 & CCGT $^{\mathrm{a}}+$ Wind \\
\hline 4 & Wind + Hydro \\
\hline 5 & $100 \%$ RES \\
\hline
\end{tabular}

Scenario evaluation was performed by an adapted version of the Multi-Criteria Decision Tool to Support Electricity Power Planning (available on http://sepp.dps.uminho.pt/), described in [4]. The criteria assumed to be relevant for this work are described in Appendix 1, along with the respective 
references from which scenario relative impacts were computed. Most of the criteria were selected following [4] proposal but a few other ones were included, namely social acceptance, backup needs, water depletion and other emissions (particulate matter and $\mathrm{SO}_{2}$ ). Criteria weighting was manually tackled considering 5 approaches: equitable weights, financial, technological, social and environmental perspectives, as described below.

Equitable approach: assumes that all criteria are equally important; according to [5], this approach produces results nearly as good as optimal weighting methods.

Economic approach: values as more important the criteria directly or indirectly related to economic impacts namely costs, investments in grid transmissions, national industry and energy dependency, employment and public health were also accounted to this analysis because employment is an economic indicator of a country and public health. Particularly, public health has been seen as a problematic topic and gaining increasing attention by governments all over the world [6].

Technical approach: reflects for example concerns on the flexibility of the system to respond to demand valuing more criteria related to the transmission network and backup needs, followed by the rate of dispatchable power and technology mix, as these last two criteria have a strong impact on security of supply.

Social approach: recognizes the importance of criteria such as social acceptance and public health, along with visual and noise impact, employment and local income and finally, land use.

Environmental approach: values the impact on environmental wellbeing, with impacts on air and soil pollution, here represented by $\mathrm{CO}_{2}, \mathrm{PM}$ and $\mathrm{SO}_{2}$ emissions, land use, noise and visual impact.

\section{RESULTS AND DISCUSSION}

The attribution of relative weights for each criterion on each approach was made on a percentage scale $(0 \%$ to $100 \%)$ and is presented in Fig.1.

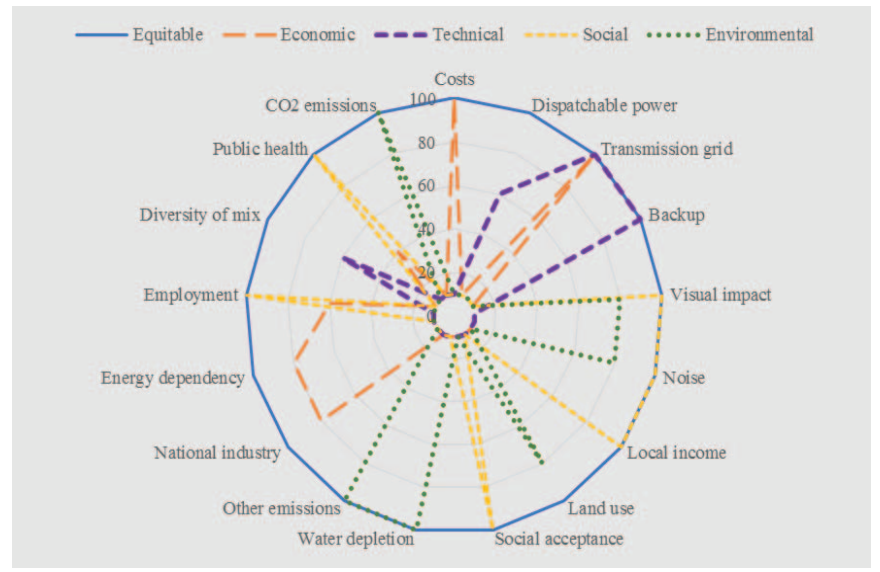

Figure 1. Relative weights of criterion for each approach.
The obtained scenarios preferences under each different approach are presented in Fig. 2 to Fig. 6. From Fig. 2 it is observed that, under an equitable approach, the preference would be the scenario with higher investments in CCGT and wind power. On the other hand, base scenario would be the worst option.

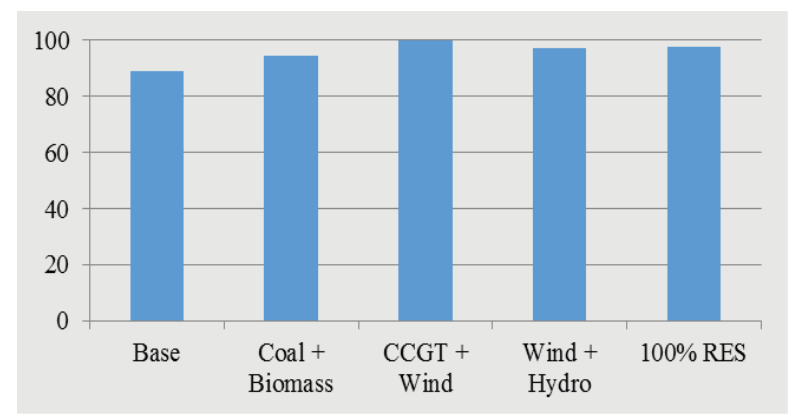

Figure 2. Scenario ranking under an equitable approach.

Under the economic perspective (Fig. 3), the base scenario ranks last. This can be a somewhat puzzling outcome as this scenario presents the lowest average cost due to the strong reliance on coal power. The main justification lies in the other criteria also considered to be relevant for the economic dimensions, as employment and public health. The best scenario is the one with higher investments on wind energy and natural gas.

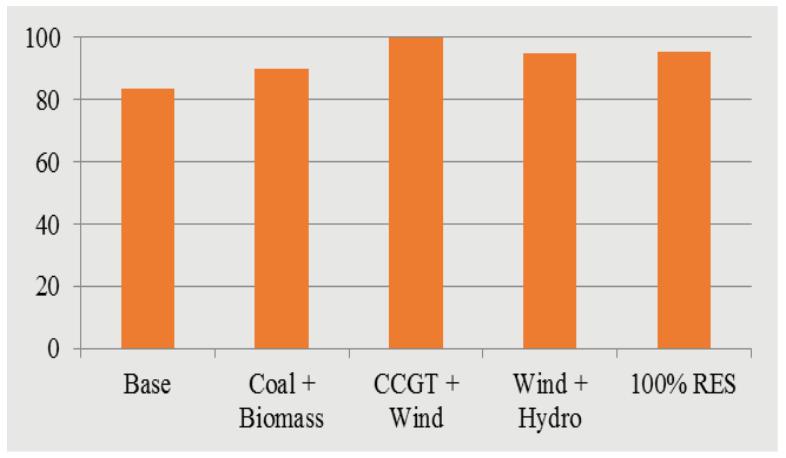

Figure 3. Scenario ranking under an economic approach.

From the technical perspective (Fig. 4), the base scenario is the best option, followed by the second scenario, i.e., scenarios with little or no need for additional backup and grid transmission investment; besides presenting a very good rate of dispatchable power and technology mix are beneficed. The $100 \%$ renewable scenario is, in opposition, the less attractive option from a technical point of view, due to the high requirements of RES technologies and the non-dispatchable nature of most of them. 


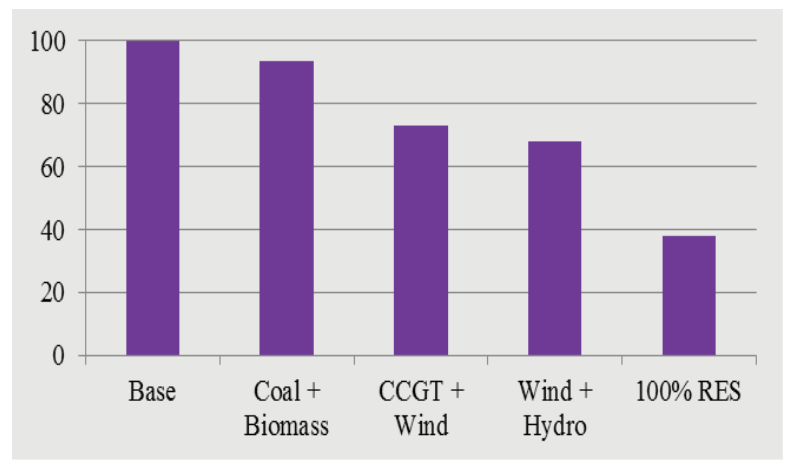

Figure 4. Scenario ranking under a technical approach.

From the results presented in Fig. 5, it was demonstrated that $100 \%$ renewable scenario was by far the best option under a social perspective.

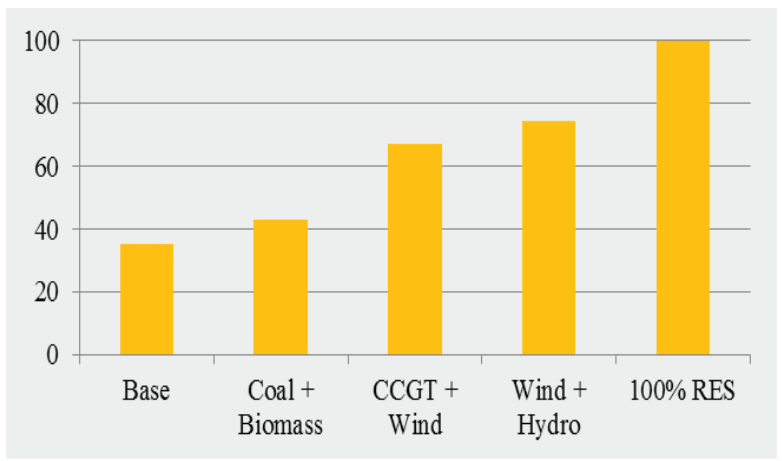

Figure 5. Scenario ranking under a social approach.

In this analysis of environmental approach (Fig. 6), the scenario with major investment in wind and natural gas resulted in the best option, as it represents a compromise solution. Although it results in higher $\mathrm{CO}_{2}$ emissions than the $100 \%$ RES scenario, the noise and visual impact are considered to be lower. Scenarios with coal power investments are not the worst options, because criteria such as noise, visual impact and land use, which benefit coal power plants when compared to RES, play an important role on an environmental perspective.

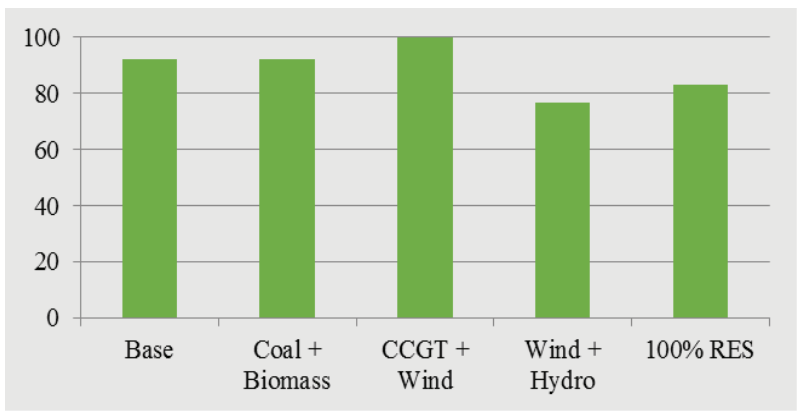

Figure 6. Scenario ranking under an environmental approach.

Table 2 presents a compilation of the results for ranking scenarios according to each analysed approach. It can be concluded that base scenario, i.e., coal power plants, is the best choice only from the technical perspective. Scenarios with $100 \%$ electricity provided by renewable sources are preferred under social approach and scenarios with major investments on wind and natural gas are the preferred ones under equitable, economic and environmental approaches.

TABLE II. RANKNG OF THE SCENARIOS EVALUATION BY EACH APPROACH.

\begin{tabular}{|c|c|c|c|c|c|}
\hline \multirow[b]{2}{*}{ Approach } & \multicolumn{5}{|c|}{ Scenarios } \\
\hline & Base & $\begin{array}{c}\text { Coal }+ \\
\text { Biomass }\end{array}$ & $\begin{array}{c}C C G T+ \\
\text { Wind }\end{array}$ & $\begin{array}{c}\text { Wind + } \\
\text { Hydro }\end{array}$ & $\begin{array}{c}100 \% \\
R E S\end{array}$ \\
\hline Equitable & 5 & 4 & 1 & 3 & 2 \\
\hline Economic & 5 & 4 & 1 & 3 & 2 \\
\hline Technical & 1 & 2 & 3 & 4 & 5 \\
\hline Social & 5 & 4 & 3 & 2 & 1 \\
\hline Environmental & 3 & 2 & 1 & 5 & 4 \\
\hline
\end{tabular}

\section{MAIN FINDINGS}

RES technologies have been presented as competitive strategies to be included in the Portuguese electricity system. Although still expensive technologies and requiring additional technical considerations, when compared to fossil fuel power plants, RES offer friendly environmental characteristics and are fundamental to achieve national targets for the $\mathrm{CO}_{2}$ emissions reduction.

In this work, the possibility and the implications of transforming the actual electricity system of Portugal, a very fossil fuel dependent system, into a low carbon one by the year 2030 was studied. Five scenarios were compared by multi-criteria decision analysis using different approaches: equitable weights, economic, technical, social and environmental approaches. 100\% RES scenario was pointed out as the best option under a social perspective, whereas base scenario was the best option under a technical approach. The remained three approaches revealed the preference for the scenario with the highest investments on CCGT and wind power units.

A remarkable outcome of the research is that even when considering an economic perspective, scenarios with a high share of RES remain more interesting than the ones based on fossil fuels. This happens because for the MCDA it was assumed that economic aspects should not be limited to the investment and operating costs but must also include criteria with direct impact on the economic performance of the country, even if this may be felt only in the medium or long term run. If externalities, related to social or environmental impacts, were monetized and included in the analysis it would be expectable that high RES scenarios would reach even more favorable results as demonstrated under the environmental and social approaches.

The work presented allowed to demonstrate how MCDA may be used to structure long term electricity decision making, using a simple and user-friendly tool. It allowed to highlight the importance of each criteria, and to analyse the 
sensitivity of the results to the different weights assigned. The use of the tool was already demonstrated for Portugal, and work is now being conducted to test its potential implementation in other countries with different energy requirements and goals.

\section{ACKNOWLEDGMENT}

The author wish to acknowledge the support of ALGORITMI, a research Centre at the University of Minho. This work is supported by National Funds through FCT Foundation for Science and Technology, under the project PEst- OE/UID/CEC00319/2013.

\section{REFERENCES}

[1] L. J. Martinez, J. H. Lambert, and C. W. Karvetski, "Scenario-informed multiple criteria analysis for prioritizing investments in electricity capacity expansion," Reliab. Eng. Syst. Saf., vol. 96, no. 8, pp. 883891, Aug. 2011.

[2] J. K. Kaldellis, A. Anestis, and I. Koronaki, "Strategic planning in the electricity generation sector through the development of an integrated Delphi-based multi-criteria evaluation model," Fuel, vol. 106, pp. 212218, Apr. 2013.

[3] S. Pereira, P. Ferreira, and A. I. Vaz, "Strategic Electricity Planning Decisions," in Conference on Sustainable Development of Energy, Water and Environment Systems, Dubrovnik, Croatia, 2011, pp. 25-29.

[4] F. Ribeiro, P. Ferreira, and M. Araújo, "Evaluating future scenarios for the power generation sector using a Multi-Criteria Decision Analysis (MCDA) tool: The Portuguese case," Energy, vol. 52, pp. 126-136, Apr. 2013.

[5] A. Maxim, "Sustainability assessment of electricity generation technologies using weighted multi-criteria decision analysis," Energy Policy, vol. 65, pp. 284-297, Feb. 2014.

[6] V. Sousa, N. M. Almeida, and L. a. Dias, "Risk-based management of occupational safety and health in the construction industry - Part 1: Background knowledge," Saf. Sci., vol. 66, pp. 75-86, Jul. 2014.

[7] M. M. Rahman, J. V. Paatero, and R. Lahdelma, "Evaluation of choices for sustainable rural electrification in developing countries: A multicriteria approach," Energy Policy, vol. 59, pp. 589-599, Aug. 2013.

[8] D. Robinson, "Living with Intermittent Renewable Power: Challenges for Spain and the EU," Oxford Energy Comment, no. June, pp. 1-14, 2013.

[9] R. Mamlook, B. a Akash, and M. S. Mohsen, "A neuro-fuzzy program approach for evaluating electric power generation systems," Energy, vol. 26, no. 6, pp. 619-632, Jun. 2001.
[10] B. a Akash, R. Mamlook, and M. S. Mohsen, "Multi-criteria selection of electric power plants using analytical hierarchy process," Electr. Power Syst. Res., vol. 52, no. 1, pp. 29-35, Oct. 1999.

[11] APPA - Spanish Renewable Energy Association, "Study of the Macroeconomic Impact of Renewable Energies in Spain Study of the macroeconomic impact of Renewable Energies in Spain," 2009.

[12] P. D. Gaspar, R. P. Mendes, and L. C. Gonçalves, "Criteria Assessment of Energy Carrier Systems Sustainability," in Energy Efficiency - A Bridge to Low Carbon Economy, Z. Morvaj, Ed. InTech, 2012.

[13] J. Sliogeriene, Z. Turskis, and D. Streimikiene, "Analysis and Choice of Energy Generation Technologies: The Multiple Criteria Assessment on the Case Study of Lithuania," Energy Procedia, vol. 32, pp. 11-20, 2013.

[14] Y.-C. Shen, C. J. Chou, and G. T. R. Lin, "The portfolio of renewable energy sources for achieving the three E policy goals," Energy, vol. 36, no. 5, pp. 2589-2598, May 2011.

[15] J. Burton and K. Hubacek, "Is small beautiful? A multicriteria assessment of small-scale energy technology applications in local governments," Energy Policy, vol. 59, no. 2, pp. 200-205, 2007.

[16] A. I. Chatzimouratidis and P. a. Pilavachi, "Decision support systems for power plants impact on the living standard," Energy Convers. Manag., vol. 64, no. x, pp. 182-198, Dec. 2012.

[17] F. Ribeiro, P. Ferreira, and M. Araújo, "The inclusion of social aspects in power planning," Renew. Sustain. Energy Rev., vol. 15, no. 9, pp. 4361-4369, Dec. 2011.

[18] N. H. Afgan and M. G. Carvalho, "Multi-criteria assessment of new and renewable energy power plants," Energy, vol. 27, no. 8, pp. 739755, Aug. 2002.

[19] D. Gallego Carrera and A. Mack, "Sustainability assessment of energy technologies via social indicators: Results of a survey among European energy experts," Energy Policy, vol. 38, no. 2, pp. 1030-1039, Feb. 2010. 


\section{APPENDIX 1 - CRITERIA DESCRIPTION FOR THE MCDA.}

\begin{tabular}{|c|c|c|}
\hline Criteria & Description & References \\
\hline Total cost (€/MWh) & $\begin{array}{l}\text { Represents the sum of the annualized costs of new installed units, as well as O\&M of all units (including fuel), } \\
\text { divided by the total amount of produced electricity in the planning period. }\end{array}$ & a \\
\hline $\begin{array}{lr}\text { Investment } & \text { in } \\
\text { transmission } & \text { grid } \\
\text { (ordinal) } & \end{array}$ & $\begin{array}{l}\text { The establishment of new electricity power infrastructures may require additional investments in the transmission } \\
\text { system, namely on grid connection, reinforcement and extension. The highest investment was assumed for solar } \\
\text { photovoltaic units, followed by mini-hydro and wind power units. }\end{array}$ & $\begin{array}{l}{[7]} \\
{[8]}\end{array}$ \\
\hline $\begin{array}{l}\text { National industry } \\
\text { (ordinal) }\end{array}$ & $\begin{array}{l}\text { For the all the stages for projection, construction and maintenance of generation infrastructures the use of industry of } \\
\text { different sectors is required. This criteria aims to capture the impact of each scenario on the dynamics of national } \\
\text { industry. Fossil fuel units were considered to have a minor impact when compared with renewables. Between these, } \\
\text { sun and wind power units have the highest impact. }\end{array}$ & $\begin{array}{l}{[9]} \\
{[10]} \\
{[11]}\end{array}$ \\
\hline Energy dependency $(\%)$ & The criteria is evaluated by the share of electricity produced from imported primary energy (coal and natural gas). & a \\
\hline Diversity of mix (ratio) & The expression used to measure the diversity of the mix was based on Shannon-Wiener index. & a \\
\hline $\begin{array}{l}\text { Rate of dispatchable } \\
\text { power }(\%)\end{array}$ & $\begin{array}{l}\text { The criteria is evaluated according to the ratio between the total installed power of dispatchable technologies (hydro } \\
\text { power with reservoir, natural gas, coal and biomass power plants) and the total installed power of the system. }\end{array}$ & a \\
\hline Employment (jobs) & $\begin{array}{l}\text { Estimated values of direct and indirect jobs in each scenario, for the project, construction and operation of the power } \\
\text { plants. }\end{array}$ & [12] \\
\hline Local income (ordinal) & $\begin{array}{l}\text { Revenues obtained as compensation for the establishment of new generation infrastructures can have a positive } \\
\text { impact in local populations, associations and municipal income. }\end{array}$ & $\begin{array}{l}{[9]} \\
{[10]} \\
{[13]} \\
{[14]}\end{array}$ \\
\hline Public health (ordinal) & $\begin{array}{l}\text { The new infrastructures of electricity production can have direct and indirect health impacts, including hospitalization } \\
\text { and medication, loss of productivity, accidents, etc. }\end{array}$ & {$[5]$} \\
\hline $\begin{array}{l}\text { Social acceptance } \\
\text { (ordinal) }\end{array}$ & $\begin{array}{l}\text { Public preference for the deployment or utilization of a certain electricity generation technology. Sun photovoltaic is } \\
\text { the most well accepted technology and fossil fuel units the least accepted. }\end{array}$ & $\begin{array}{l}{[12]} \\
{[15]} \\
{[16]} \\
{[17]}\end{array}$ \\
\hline Land use $\left(\mathrm{x} 1000 \mathrm{~km}^{2}\right)$ & Represents the required land for de deployment of new infrastructures. & {$[18]$} \\
\hline Backup needs $(\%)$ & $\begin{array}{l}\text { Insure overall grid stability in the long term in the context of a growing share of intermittent generation from some } \\
\text { renewable energy sources. Higher shares of intermittent RES power production can require higher backup capacity. } \\
\text { This criteria was assessed from the ratio between total installed power of solar, wind and mini-hydro power units and } \\
\text { total installed power for the entire period. }\end{array}$ & $\mathrm{a}$ \\
\hline Visual impact (ordinal) & $\begin{array}{l}\text { The establishment and the functioning of new power units can cause changes on the landscape having thus a visual } \\
\text { impact. }\end{array}$ & [19] \\
\hline Noise (ordinal) & $\begin{array}{l}\text { The normal functioning of new generation infrastructures can have noise impact, causing annoyance to local } \\
\text { population. }\end{array}$ & {$[15]$} \\
\hline $\begin{array}{l}\text { Water } \\
\text { (ordinal) }\end{array}$ & $\begin{array}{l}\text { Ratio between water consumption by all power plants during the overall planning period and the total electricity } \\
\text { produced. }\end{array}$ & $\mathrm{b}$ \\
\hline $\begin{array}{ll}\mathrm{CO}_{2} & \text { emissions } \\
(\mathrm{ton} / \mathrm{GWh}) & \end{array}$ & $\begin{array}{l}\text { Ratio between } \mathrm{CO}_{2} \text { emissions released by all power plants during the overall planning period and the total electricity } \\
\text { produced. }\end{array}$ & a \\
\hline $\begin{array}{l}\text { Other } \\
\text { (ordinal) }\end{array} \quad$ emissions & $\begin{array}{l}\text { Ratio between particulate matter }(\mathrm{PM}) \text { and } \mathrm{SO}_{2} \text { emissions released by all power plants during the overall planning } \\
\text { period and the total electricity produced. }\end{array}$ & $\mathrm{b}$ \\
\hline
\end{tabular}

